\title{
Fungitoxicidade de grupos químicos sobre Myrothecium roridum in vitro e sobre a mancha-de-mirotécio em algodoeiro
}

\author{
Juliano César da Silva( ${ }^{(1)}$, Maurício Conrado Meyer ${ }^{(2)}$, Wirton Macedo Coutinho( ${ }^{(3)}$ e Nelson Dias Suassuna ${ }^{(3)}$
}

(1)SLC Agrícola, Caixa Postal 118, CEP 65800-000 Balsas, MA. E-mail: julianopb@slcagricola.com.br (2)Embrapa Soja, Caixa Postal 131, CEP 65800-000 Balsas, MA. E-mail: mauricio@embrapabalsas.com.br (3)Embrapa Algodão, Caixa Postal 174, CEP 58107-720 Campina Grande, PB. E-mail: wirton@cnpa.embrapa.br, suassuna@cnpa.embrapa.br

\begin{abstract}
Resumo - O objetivo deste trabalho foi avaliar a fungitoxicidade de produtos pertencentes aos grupos dos benzimidazóis, triazóis, estrobilurinas, isoftalonitrilas e ditiocarbamatos sobre a germinação conidial e o crescimento micelial in vitro de isolados de Myrothecium roridum e, in vivo, sobre a severidade da mancha-de-mirotécio em plantas de algodoeiro. Nos testes in vitro os fungicidas foram solubilizados em meio BDA, utilizando-se as concentrações de 0,1,1,10 e $100 \mathrm{mg} \mathrm{L}^{-1}$ de ingrediente ativo. A fungitoxidade dos produtos foi avaliada por meio da $\mathrm{ED}_{50}$ (dose necessária para inibir $50 \%$ da germinação conidial ou crescimento micelial). Em casa de vegetação, estimou-se a severidade da mancha-de-mirotécio pela porcentagem de área foliar lesionada nas plantas de algodoeiro tratadas antes (preventivo) e depois (curativo) da inoculação do patógeno. Os fungicidas tiofanato metílico, carbendazim, metconazol, tiofanato metílico + clorotalonil, piraclostrobina + epoxiconazol, piraclostrobina + metiram, triflostrobina + propiconazol e tebuconazol inibiram com alta eficácia $\left(E_{50}<1 \mathrm{mg} \mathrm{L}^{-1}\right)$, ou com eficácia $\left(\mathrm{ED}_{50}\right.$ entre 1 e $\left.10 \mathrm{mg} \mathrm{L}^{-1}\right)$, a germinação conidial e o crescimento micelial in vitro de M. roridum. Os fungicidas piraclostrobina + epoxiconazol, tebuconazol, metconazol e azoxistrobina + ciproconazol são os mais eficazes em testes in vivo. O tratamento preventivo é mais eficaz que o curativo.
\end{abstract}

Termos para indexação: Gossypium hirsutum, germinação conidial, crescimento micelial, controle químico.

\section{Fungitoxicity of chemical groups on Myrothecium roridum in vitro and on myrothecium leaf spot on cotton plants}

\begin{abstract}
The objective of this work was to evaluate the toxicity of benzimidazoles, triazoles, strobilurins, isoftalonitrils and ditiocarbamats on Myrothecium roridum conidial germination and micelial growth in vitro, and the myrothecium leaf spot severity on cotton plants. On in vitro tests, fungicides were solubilized in PDA media at the following concentrations: $0.1,1,10$ and $100 \mathrm{mg} \mathrm{L}^{-1}$. The toxicity of the products were evaluated by the $\mathrm{ED}_{50}$ rate (required for inhibiting $50 \%$ of the conidial germination or mycelial growth). In greenhouse tests, the severity of myrothecium leaf spot was quantified by measuring the leaf area affected by the pathogen in cotton plants sprayed before (preventive) and after (curative) the pathogen inoculation. The fungicides thiophanate methyl, carbendazim, metconazole, thiophanate methyl + chlorothalonil, pyraclostrobin + epoxyconazole, pyraclostrobin + metiran, trifloxystrobin + propiconazole, and tebuconazole were highly efficient $\left(\mathrm{ED}_{50}<1 \mathrm{mg} \mathrm{L}{ }^{-1}\right)$ or efficient $\left(\mathrm{ED}_{50}\right.$ between 1 and $\left.10 \mathrm{mg} \mathrm{L}^{-1}\right)$ inhibiting conidial germination and mycelial growth of $M$. roridum isolates. In greenhouse tests, fungicides pyraclostrobin + epoxyconazole, tebuconazole, metconazole, and azoxystrobin + cyproconazole are the most efficient against myrothecium leaf spot disease. Preventive treatment is more efficient than curative.
\end{abstract}

Index terms: Gossypium hirsutum, conidial germination, mycelial growth, chemical control.

\section{Introdução}

A mancha-de-mirotécio, causada por Myrothecium roridum Tode ex Fr., foi relatada na cultura do algodoeiro pela primeira vez na Índia (Munjal, 1960). No Brasil, sua ocorrência foi observada na safra 2003/2004, em áreas de produção de algodão nos estados da Bahia, Mato Grosso e Maranhão, atingindo, neste último, proporções epidêmicas, com perdas estimadas de até $60 \%$ na produção (Chitarra \& Meyer, 2004). 
O agente etiológico da mancha-de-mirotécio é um fungo de solo, saprófita, que sobrevive em restos culturais e pode ser transmitido por sementes (Gazzoni \& Yorinori, 1995). Sua dispersão ocorre de partes infectadas das plantas para as partes sadias, principalmente por meio de respingos de água das chuvas, orvalho ou de irrigação. O fungo é encontrado em regiões de clima temperado e tropical, com uma gama de hospedeiros vasta, que inclui solanáceas e cucurbitáceas (Hillocks, 1992).

A temperatura ótima para germinação de esporos de isolados do patógeno, oriundos de regiões de clima temperado, é de $29^{\circ} \mathrm{C}$; isolados provenientes de regiões de clima tropical podem ter crescimento ótimo em temperaturas mais elevadas (Hillocks, 1992). Os sintomas da doença ocorrem inicialmente nas folhas e, em seguida, nas brácteas, maçãs, pecíolos e caules, sendo caracterizados por manchas circulares com coloração violeta a avermelhada nas margens e marrom a negras no centro, à medida que evoluem. As lesões podem atingir $3 \mathrm{~cm}$ de diâmetro, com áreas translúcidas ao seu redor. Esporodóquios escuros também são observados sobre as lesões, sendo inicialmente arredondados e, à medida que se desenvolvem, tornam-se irregulares, com hifas de coloração branca ao redor (Hillocks, 1992).

A mancha-de-mirotécio ocorre com mais freqüência em plantas submetidas a algum tipo de estresse (Chitarra \& Meyer, 2004); entretanto, tem-se verificado a ocorrência da doença, em diversas regiões produtoras, mesmo em plantas não submetidas a estresse, embora não haja relatos de perdas na produção na maioria dessas áreas.

Em virtude de a doença ter sido verificada recentemente no Brasil, informações sobre métodos de controle são restritas. Não existem informações sobre a resistência genética à mancha-de-mirotécio em cultivares de algodoeiro e, tampouco, fungicidas químicos registrados para seu controle.

Embora não seja possível dimensionar com exatidão a importância da mancha-de-mirotécio nas próximas safras da cultura, a reincidência é provável, sobretudo em anos com alta precipitação pluvial e altas temperaturas, em função da provável suscetibilidade das variedades utilizadas e da continuidade espacial dos cultivos. O uso de medidas preventivas, como rotação de culturas, tratamento de sementes, eliminação de soqueiras e controle químico é recomendável.

Fungicidas químicos com ingredientes ativos à base de iprodiona, clorotalonil, tetraconazole, azoxistrobina e clorotalonil + tiofanato metílico têm sido utilizados no controle da mancha-de-mirotécio na Índia (Singh, 1998).

O objetivo deste trabalho foi avaliar a fungitoxicidade de produtos pertencentes aos grupos químicos dos benzimidazóis, triazóis, estrobilurinas, isoftalonitrilas e ditiocarbamatos sobre a germinação conidial e o crescimento micelial de $M$. roridum, e sobre a severidade da mancha-de-mirotécio em plantas de algodoeiro tratadas de forma preventiva e curativa.

\section{Material e Métodos}

Os experimentos foram realizados em laboratório e em casa de vegetação do Setor de Fitopatologia da Embrapa Algodão, no Município de Campina Grande, PB.

\section{Testes in vitro}

Foram utilizados dois isolados de $M$. roridum: CNPA 0012 (obtido de folhas de soja cv. Sambaíba, Município de Riachão, MA) e CNPA 0014 (obtido de folhas de algodoeiro cv. Sure Grow 821, Município de Tasso Fragoso, MA). Realizou-se o isolamento indireto a partir dos órgãos com sintomas da doença. Fragmentos de tecidos foram desinfectados por imersão (um minuto) em álcool 70\%, hipoclorito de sódio 1\% e água destilada esterilizada, em seqüência, e transferidos para placas de Petri contendo meio de cultura BDA (Batata Dextrose Ágar).

Os isolados foram preservados pelo método de Castellani. Uma suspensão de esporos foi preparada, adicionando-se $20 \mathrm{~mL}$ de água destilada e esterilizada em placas de Petri com os isolados cultivados em meio BDA, sob condições controladas (temperatura de $27 \pm 2^{\circ} \mathrm{C}$ e fotoperíodo de 12 horas), durante sete dias. Os conídios foram liberados das colônias fúngicas cultivadas sobre o meio de cultura com uma alça de Drigalski, e a suspensão resultante, filtrada em uma camada dupla de gaze esterilizada. A suspensão de conídios foi ajustada para $10^{6}$ esporos por $\mathrm{mL}$, utilizandose hemacitômetro.

Para avaliar a fungitoxicidade in vitro dos diferentes grupos químicos sobre a germinação conidial de isolados de $M$. roridum, os fungicidas testados foram solubilizados em água destilada e adicionados ao meio de cultura Ágar-Água (AA), obtendo-se as concentrações de 0,1, 1 , 10 e $100 \mathrm{mg} \mathrm{L}^{-1}$ de ingrediente ativo. O meio de cultura, 
nas diferentes concentrações dos fungicidas testados, foi vertido em lâminas de microscopia, utilizando-se uma pipeta automática. Adicionaram-se, sobre o meio de cultura ajustado às diferentes concentrações de ingrediente ativo, $100 \mu \mathrm{L}$ da suspensão de esporos dos isolados de $M$. roridum. No tratamento testemunha, alíquotas de $100 \mu \mathrm{L}$ da suspensão de conídios foram distribuídas sobre lâminas de miscroscopia, contendo meio de cultura AA, sem adição de fungicida. As lâminas foram acondicionadas em caixas de plástico, tipo Gerbox, e mantidas em temperatura de $28 \pm 2^{\circ} \mathrm{C}$ durante 22 horas; depois desse período, foi adicionada uma gota de lactofenol sobre cada lâmina. A germinação dos conídios foi avaliada ao microscópio óptico, considerando-se como germinados, conídios com tubo germinativo de tamanho igual ou superior ao seu comprimento.

Os fungicidas testados sobre o crescimento micelial de isolados de $M$. roridum foram solubilizados em água destilada e adicionados ao meio de cultura BDA fundido (temperatura aproximada de $45^{\circ} \mathrm{C}$ ), obtendo-se concentrações de $0,1,1,10$ e $100 \mathrm{mg} \mathrm{L}^{-1}$ de ingrediente ativo. O meio de cultura nas diferentes concentrações dos fungicidas foi vertido em placas de Petri de $9 \mathrm{~cm}$ de diâmetro, utilizando-se $15 \mathrm{~mL}$ por placa. No centro de cada placa foi disposto um disco com 5 mm de diâmetro, retirado de culturas com crescimento ativo dos isolados CNPA 0012 e CNPA 0014 de M. roridum, os quais foram cultivados em meio BDA sob condições controladas $\left(27 \pm 2^{\circ} \mathrm{C}\right.$ e fotoperíodo de 12 horas), durante sete dias. No tratamento testemunha, não houve adição de fungicida. As placas foram mantidas em temperatura de $25^{\circ} \mathrm{C}$, sob fotoperíodo de 12 horas, durante sete dias. Depois desse período, foi mensurado o diâmetro médio das colônias.

O delineamento experimental foi o inteiramente casualizado, com 14 tratamentos e cinco repetições, sendo cada lâmina e cada placa de Petri uma unidade amostral para germinação conidial e crescimento micelial, respectivamente. Os valores de inibição de porcentagem de germinação conidial e de crescimento micelial, para cada fungicida, foram obtidos pela diferença entre a porcentagem de germinação ou diâmetro médio das colônias, nas concentrações dos fungicidas, e o tratamento testemunha. As médias de cada tratamento foram submetidas à análise de próbites e os valores de $\mathrm{ED}_{50}$ - dosagem necessária para inibir $50 \%$ da germinação conidial ou do crescimento micelial - foram estimados por meio do procedimento PROBIT do software estatístico SAS, versão 8.0. Depois do cálculo da $\mathrm{ED}_{50}$, os fungicidas foram classificados em quatro categorias, de acordo com a escala de Edgington et al. (1971), modificada: $\mathrm{ED}_{50} \geq 50 \mathrm{mg} \mathrm{L}^{-1}$, ineficaz; $\mathrm{ED}_{50}$ entre 10 e $50 \mathrm{mg} \mathrm{L}^{-1}$, moderadamente eficaz; $\mathrm{ED}_{50}$ entre 1 e $10 \mathrm{mg} \mathrm{L}^{-1}$, eficaz; e $E D_{50}<1 \mathrm{mg} \mathrm{L}^{-1}$, altamente eficaz.

\section{Testes em casa de vegetação}

Em vasos de plástico, foram adicionados $4 \mathrm{~kg}$ de uma mistura de solo e esterco na proporção de 3:1; em seguida, foram semeadas cinco sementes de algodoeiro da cultivar Delta Pine Acala 90. Depois da semeadura, os vasos foram acondicionados em casa de vegetação, mantendo-se duas plantas por vaso.

Uma mistura de sete isolados de $M$. roridum foi utilizada como inóculo. Os isolados CNPA 0009, CNPA 0013, CNPA 0014 e CNPA 0016 foram obtidos de folhas de algodoeiro das cultivares Fiber Max 966 (Itiquira, MT), Delta Pine Acala 90 (Riachão, MA), Sure Grow 821 (Tasso Fragoso, MA) e Fiber Max 966 (Rondonópolis, MT), respectivamente. Os isolados CNPA 0011 e CNPA 0015 foram obtidos de brácteas e maçãs da cultivar Delta Pine Acala 90, nos municípios de Riachão e Tasso Fragoso, respectivamente, enquanto o isolado CNPA 0012 foi obtido de folhas da cultivar de soja BRS Sambaíba, coletadas em Riachão. Os isolamentos e o preparo das suspensões de conídios foram realizados conforme descrito anteriormente; logo depois, misturaram-se às suspensões de conídios de cada isolado, ajustando para $10^{6}$ esporos por mL. Utilizou-se um pulverizador costal manual, com capacidade para $5 \mathrm{~L}$, para inocular o fungo sobre as plantas. A suspensão de conídios foi pulverizada nas plantas, até o ponto de escorrimento.

O efeito preventivo dos tratamentos com fungicidas foi avaliado em plantas de algodoeiro no estágio V6 (Marur \& Ruano, 2001), pulverizadas três dias antes da inoculação. Depois de submetidas à inoculação, as plantas foram acondicionadas em sala climatizada sob condições controladas (temperatura de $25 \pm 2^{\circ} \mathrm{C}$ e umidade relativa de $90 \%$ ), durante oito dias; depois desse período, estimouse visualmente a porcentagem de área foliar lesionada.

No ensaio para avaliar o efeito curativo dos fungicidas, as plantas de algodoeiro previamente submetidas à inoculação no estádio fenológico V4 (Marur \& Ruano, 
2001), foram pulverizadas com os fungicidas, quando aproximadamente 5\% de área foliar estava lesionada. As plantas foram mantidas em sala climatizada (temperatura de $25 \pm 2^{\circ} \mathrm{C}$ e umidade de $90 \%$ ), durante oito dias. A porcentagem de área foliar lesionada foi estimada visualmente oito dias após a inoculação do patógeno.

Tanto no ensaio preventivo quanto no curativo, os fungicidas foram aplicados por meio de um pulverizador costal, pressurizado com $\mathrm{CO}_{2}$, calibrado para a vazão de $200 \mathrm{~L} \mathrm{ha}^{-1}$, com bico do tipo leque AVI 110-02.

O delineamento experimental utilizado foi o inteiramente casualizado, com dez tratamentos e cinco repetições; a parcela foi composta por um vaso contendo duas plantas. Em razão dos dados não terem homogeneidade de variância, utilizou-se o teste de Kruskal-Wallis, a 5\% de probabilidade, para análise e comparação das médias dos tratamentos.

\section{Resultados e Discussão}

A fungitoxicidade in vitro dos produtos testados sobre a germinação conidial dos isolados de $M$. roridum diferiu entre tratamentos (Tabela 1). Os fungicidas difenoconazol e ciproconazol foram classificados, respectivamente, como ineficaz e moderadamente eficaz, para o isolado CNPA 0012, enquanto os outros fungicidas foram classificados como eficazes (tiofanato metílico, tetraconazol) ou altamente eficazes (carbendazim, flutriafol, metconazol, tiofanato metílico + clorotalonil, piraclostrobina + epoxiconazol, piraclostrobina + metiram e trifloxistrobina + propiconazol), para ambos os isolados testados. A eficácia dos fungicidas tebuconazol, clorotalonil e azoxistrobina + ciproconazol diferiu com relação aos isolados avaliados, tendo sido eficazes na inibição da germinação do isolado CNPA 0014 e altamente eficazes com relação ao isolado CNPA 0012.

Nos testes de inibição do crescimento micelial in vitro (Tabela 1), os fungicidas flutriafol, ciproconazol, tetraconazol e clorotalonil foram ineficazes para ambos os isolados, enquanto tiofanato metílico e tiofanato metílico + clorotalonil foram eficazes. O único tratamento fungicida altamente eficaz para os dois isolados testados foi piraclostrobina + epoxiconazol; os fungicidas carbendazim, tebuconazol, metconazol e trifloxistrobina + propiconazol foram eficazes na inibição do crescimento micelial do isolado CNPA 0012 e altamente eficazes em relação ao isolado CNPA 0014; ao contrário, piraclostrobina + metiram foi eficaz na inibição do crescimento micelial do isolado CNPA 0014 e altamente eficaz quanto ao isolado CNPA 0012. Os fungicidas difenoconazole e azoxistrobina + ciproconazol foram classificados como moderadamente eficazes e eficazes na inibição micelial dos isolados CNPA 0012 e CNPA 0014, respectivamente.

As diferenças de fungitocixidade de um mesmo produto sobre a inibição da germinação conidial, ou crescimento micelial, dos isolados avaliados de $M$. roridum, podem estar relacionadas à variabilidade genética do fungo e, em conseqüência, à maior ou menor sensibilidade desses isolados aos fungicidas testados. $\mathrm{O}$ fato de os isolados utilizados serem oriundos de diferentes espécies hospedeiras e cultivares, e a possibilidade de existirem patótipos de $M$. roridum

Tabela 1. Dosagem necessária $\left(\mathrm{mg} \mathrm{L}^{-1}\right)$ de diferentes fungicidas para inibir em $50 \%$ a germinação conidial e o crescimento micelial, in vitro, dos isolados CNPA 0012 e CNPA 0014 de Myrothecium roridum.

\begin{tabular}{|c|c|c|c|c|c|}
\hline \multirow[t]{2}{*}{ Tratamento } & \multirow[t]{2}{*}{ Grupo químico } & \multicolumn{2}{|c|}{ Germinação conidial } & \multicolumn{2}{|c|}{ Crescimento micelial } \\
\hline & & CNPA 0012 & CNPA 0014 & CNPA 0012 & CNPA 0014 \\
\hline Carbendazim & Benzimidazol & 0,97 & 0,15 & 1,50 & 0,37 \\
\hline Tiofanato metílico & Benzimidazol & 1,28 & 1,21 & 6,75 & 1,47 \\
\hline Tebuconazol & Triazol & 0,77 & 1,87 & 2,59 & 0,71 \\
\hline Flutriafol & Triazol & 0,19 & 0,25 & 251,75 & 66,63 \\
\hline Metconazol & Triazol & 0,04 & 0,04 & 1,27 & 0,30 \\
\hline Difenoconazol & Triazol & $69.551,00$ & 9,87 & 46,48 & 3,16 \\
\hline Ciproconazol & Triazol & 11,20 & 4,42 & 598,20 & 806,28 \\
\hline Tetraconazol & Triazol & 1,80 & 1,66 & 603,03 & 407,34 \\
\hline Clorotalonil & Isoftalonitrila & 0,93 & 1,54 & $2.952,00$ & 319,29 \\
\hline Tiofanato metílico + clorotalonil & Benzimidazol + isoftalonitrila & 0,56 & 0,51 & 4,56 & 7,55 \\
\hline Piraclostrobina + epoxiconazol & Estrobilurina + triazol & 0,10 & 0,07 & 0,39 & 0,16 \\
\hline Piraclostrobina + metiram & Estrobilurina + ditiocarbamato & 0,99 & 0,07 & 0,79 & 3,36 \\
\hline Trifloxistrobina + propiconazol & Estrobilurina + triazol & 0,11 & 0,10 & 2,21 & 0,32 \\
\hline Azoxistrobina + ciproconazol & Estrobilurina + triazol & 0,51 & 2,00 & 33,55 & 3,16 \\
\hline
\end{tabular}


(Taneja et al., 1990) corroboram essa hipótese. Em estudos semelhantes, a eficácia de fungicidas químicos também variou em relação a diferentes isolados de um mesmo patógeno. Parisi et al. (1999) constataram diferenças em relação à fungitoxicidade de quintozeno, procimidona, tiram e iprodiona sobre a inibição micelial in vitro de quatro isolados de Phomopsis phaseoli f. sp. meridionalis e Phomopsis sojae, enquanto LaMondia \& Douglas (1997) detectaram diferenças na eficácia dos fungicidas benomil e tiofanato metílico, vinclozolin e iprodione sobre o crescimento micelial in vitro de 45 isolados de Botrytis cinerea.

Todos os fungicidas testados in vitro podem atuar como protetores ou curativos. No primeiro caso, a ação tóxica do produto é exercida sobre a germinação dos esporos, na formação do tubo germinativo e do apressório e, no segundo, o desenvolvimento do haustório, ou crescimento micelial, é inibido pelo fungicida. Os fungicidas testados foram mais eficazes na inibição da germinação conidial que na inibição do crescimento micelial dos isolados de M. roridum.

Houve diferença de fungitoxicidade entre os tratamentos empregados tanto de forma preventiva quanto curativa, sobre a mancha-de-mirotécio (Tabela 2). Com exceção do fungicicida flutriafol, aplicado de forma preventiva, todos os demais tratamentos reduziram significativamente $(\mathrm{p}<0,05)$ a porcentagem de área foliar lesionada, quando comparados à testemunha.

Tanto no tratamento preventivo quanto no curativo, os fungicidas mais eficazes na redução da severidade da mancha-de-mirotécio, em plantas de algodoeiro, foram piraclostrobina + epoxiconazol, tebuconazol, metconazol e azoxistrobina + ciproconazol. Esses fungicidas também foram classificados como eficazes ou altamente eficazes nos testes de inibição da germinação conidial e crescimento micelial in vitro, com exceção da mistura de azoxistrobina + ciproconazol, que foi classificada como moderadamente eficaz na inibição micelial do isolado CNPA 0012 (Tabela 1).

O tratamento preventivo, quando comparado com o curativo, é mais eficaz no controle da mancha-demirotécio, independentemente do produto utilizado. Neste estudo, a redução da área foliar lesionada pelo patógeno foi muito mais acentuada quando se utilizaram os fungicidas preventivamente (Tabela 2). No tratamento preventivo, os quatro fungicidas mais eficazes no controle da mancha-de-mirotécio (azoxistrobina + ciproconazol, metconazol, tebuconazol e piraclostrobina + epoxiconazol) reduziram a porcentagem de área foliar lesionada em aproximadamente 50 vezes, quando comparados com a testemunha. No tratamento curativo, não se constatou o mesmo desempenho desses fungicidas que, apesar de terem sido eficazes no controle da doença, reduziram em apenas quatro vezes, aproximadamente, a porcentagem de área foliar lesionada, quando comparados com a testemunha.

Nos testes realizados in vitro, foi mais comum o melhor desempenho (menor $\mathrm{ED}_{50}$ ) dos fungicidas sobre a germinação conidial do que sobre o crescimento micelial de $M$. roridum, o que pode explicar porque, nos testes in vivo, o controle preventivo foi mais eficaz que o curativo. A menor porcentagem de área foliar lesionada nas plantas de algodoeiro tratadas de forma preventiva

Tabela 2. Porcentagem de área foliar lesionada (PAFL) com a mancha-de-mirotécio em plantas de algodoeiro tratadas com diversos fungicidas antes (preventivo) e após (curativo) a inoculação de Myrothecium roridum ${ }^{(1)}$.

\begin{tabular}{|c|c|c|c|c|}
\hline \multirow[t]{2}{*}{ Tratamento } & \multirow[t]{2}{*}{ Grupo químico } & \multirow[t]{2}{*}{ Dose $\left(\mathrm{g} \mathrm{ha}^{-1}\right)$} & \multicolumn{2}{|c|}{ PAFL } \\
\hline & & & Tratamento preventivo & Tratamento curativo \\
\hline Testemunha & - & - & $27,8 \mathrm{a}$ & $43,5 \mathrm{a}$ \\
\hline Flutriafol & Triazol & 75 & $18,6 \mathrm{ab}$ & $22,3 b c$ \\
\hline Carbendazim & Benzimidazol & 750 & $5,1 \mathrm{~b}$ & $25,5 \mathrm{~b}$ \\
\hline Tiofanato metílico & Benzimidazol & 750 & $1,8 \mathrm{c}$ & $21,9 \mathrm{c}$ \\
\hline Trifloxistrobina + propiconazol & Estrobilurina + triazol & $50+50$ & $1,3 \mathrm{~cd}$ & $21,4 \mathrm{c}$ \\
\hline Trifloxistrobina + ciproconazol & Estrobilurina + triazol & $56,25+24$ & $1,5 \mathrm{de}$ & $15,5 \mathrm{~d}$ \\
\hline Azoxistrobina + ciproconazol & Estrobilurina + triazol & $60+24$ & $0,5 f$ & $13,6 \mathrm{de}$ \\
\hline Metconazol & Triazol & 35 & $0,8 \mathrm{ef}$ & $12,5 \mathrm{e}$ \\
\hline Tebuconazol & Triazol & 100 & $0,5 f$ & $12,8 \mathrm{e}$ \\
\hline Piraclostrobina + epoxiconazol & Estrobilurina + triazol & $66,5+25$ & $0,3 \mathrm{f}$ & $12,8 \mathrm{e}$ \\
\hline
\end{tabular}

(1)Médias seguidas da mesma letra, na coluna, não diferem entre si pelo teste de Kruskal-Wallis, a 5\% de probabilidade. 
está, provavelmente, associada à redução da viabilidade dos esporos e, em conseqüência, do inóculo inicial do patógeno por esses fungicidas, inibindo ou retardando a progressão da doença. No tratamento curativo, houve desenvolvimento de infecção antes da aplicação de fungicidas, e esse fato acarretou algum dano às plantas, e também contribuiu para maior severidade da doença.

A proteção da planta pela aplicação do produto antes da deposição do patógeno, ou em baixa severidade da doença, além de retardar o início da epidemia, diminui a chance de um isolado resistente predominar nessas populações. A estratégia de se utilizar fungicidas antes da penetração e colonização de $M$. roridum, em áreas com alta pressão de inóculo e condições ambientais favoráveis ao desenvolvimento de epidemias, pode reduzir o progresso da doença. A mancha-de-mirotécio é influenciada por temperaturas elevadas $\left(28-30^{\circ} \mathrm{C}\right)$ e alta umidade relativa (90-100\%); portanto, a aplicação preventiva dos produtos adequados, nessas condições ambientais, poderá ser crucial no controle da doença.

A utilização de fungicidas com eficácia comprovada, e que possuam diferentes modos de ação, é importante em relação ao manejo de resistência de fungos a fungicidas. Os fungicidas utilizados são classificados como de alto risco (benzimidazóis e estrobilurinas), risco moderado (triazóis) e baixo risco (dicarboximidas e isoftalonitrila), na indução de populações resistentes de fungos (Brent \& Hollomon, 1998; Gisi et al., 2000; Delen \& Tosun, 2003). Esta classificação se baseia no conhecimento da ação bioquímica do produto.

Com os fungicidas pertencentes ao grupo dos benzimidazóis e estrobilurinas, cujo modo de ação se restringe a um sítio específico no patógeno alvo, o risco de induzir populações resistentes é maior que com aqueles que atuam em múltiplos sítios, a exemplo dos triazóis, ditiocarbamatos e isoftalonitrila (Brent \& Hollomon, 1998; Gisi et al., 2000; Delen \& Tosun, 2003). Nesses casos, alternar fungicidas com diferentes modos de ação ou utilizar misturas de dois princípios ativos, que tenham efeito sinérgico, é uma medida recomendável no manejo da resistência de $M$. roridum a fungicidas.

Apesar de eficazes no controle da mancha-demirotécio, os fungicidas devem ser utilizados em última instância. Plantar em áreas sem histórico de epidemias causadas por $M$. roridum e em condições desfavoráveis ao seu desenvolvimento são medidas que podem otimizar o manejo dessa doença. Quando for necessário o emprego de fungicidas, deve-se priorizar os que possam ser utilizados simultaneamente no controle de várias doenças. Os fungicidas considerados eficazes no controle da mancha-de-mirotécio, neste estudo, também o são no controle de outras doenças foliares da cultura do algodão, tais como as manchas-de-ramulária, de alternária e de estenfílio (Suassuna \& Iamamoto, 2004).

\section{Conclusões}

1. Os fungicidas tiofanato metílico, carbendazim, metconazol, tiofanato metílico + clorotalonil, piraclostrobina + epoxiconazol, piraclostrobina + metiram, triflostrobina + propiconazole e tebuconazole inibem, com alta eficácia ou com eficácia, a germinação conidial e crescimento micelial in vitro de M. roridum.

2. Os fungicidas piraclostrobina + epoxiconazol, tebuconazol, metconazol e azoxistrobina + ciproconazol são eficazes no controle da mancha-de-mirotécio em algodoeiro.

3. O tratamento preventivo é mais eficaz que o curativo no controle da mancha-de-mirotécio do algodoeiro, independentemente do fungicida utilizado.

\section{Referências}

BRENT, K.J.; HOLLOMON, D.J. Fungicide resistance: the assessment of risk. Brussels: Global Crop Protection Federation, 1998. 48p.

CHITARRA, L.G.; MEYER, M.C. Novo e sem controle. Cultivar Grandes Culturas, n.62, p.16-18, 2004.

DELEN, N.; TOSUN, N. Fungicidas: mecanismos de ação e resistência. Parte 1: Fungicidas com mecanismos de ação nãoespecífica. Revisão Anual de Patologia de Plantas, v.11, p.43-69, 2003.

EDGINGTON, L.V.; KNEW, K.L.; BARRON, G.L. Fungitoxic spectrum of benzimidazole compounds. Phytophatology, v.61, p.4244, 1971.

GAZZONI, D.L.; YORINORI, J.T. Manual de identificação de pragas e doenças de soja. Brasília: Embrapa-SPI, 1995. 128p.

GISI, U.; CHIN, K.M.; KNAPOVA, G.; KUNG FARBER, R.; MOHR, U.; PARISI, S.; SIEROTZKI, H.; STEINFELD, U. Recent developments in elucidating modes of resistance to phenylamide, DMI and strobilurin fungicides. Crop Protection, v.19, p.863-872, 2000.

HILLOCKS, R.J. Fungal diseases of the leaf. In: HILLOCKS, R.J. (Ed.). Cotton diseases. Wallingford: CAB International, 1992. p.191238.

LaMONDIA, J.A.; DOUGLAS, S.M. Sensitivity of Botrytis cinerea from Connecticut greenhouses to benzimidazole and dicarboximide fungicides. Plant Disease, v.81, p.729-732, 1997. 
MARUR, C.J.; RUANO, O. A reference system for determination of cotton plant development. Revista de Oleaginosas e Fibrosas, v.5, p.313-317, 2001.

MUNJAL, R.L. A commonly occurring leaf spot disease caused by Myrothecium roridum Tode ex Fr. Indian Phytopathology, v.13, p.150-155, 1960.

PARISI, J.J.D.; MENTEM, J.O.M.; MARTINS, M.C. Sensibilidade in vitro e in vivo de Phomopsis sojae e Phomopsis phaseoli f.sp. meridionalis a fungicidas. Fitopatologia Brasileira, v.24, p.25-30, 1999.
SINGH, S.N. Efficacy of different fungicides against three different isolates of Myrothecium roridum, in vitro and in vivo. Indian Journal of Plant Protection, v.26, p.72-74, 1998.

SUASSUNA, N.D.; IAMAMOTO, M.M. Doenças foliares do algodoeiro. In: SILVA FILHO, J.L.; PEDROSA, M.B. (Coord.). Resultados de pesquisa com a cultura do algodão no Oeste da Bahia: safra 2003/2004. Campina Grande: Embrapa Algodão, 2004. p.107-111. (Embrapa Algodão. Documentos, 133).

TANEJA, N.K.; RAJ, S.; SETH, P.K. Existence of pathotypes in Myrothecium roridum. Indian Phytopathology, v.43, p.464-466, 1990.

$\overline{\text { Recebido em } 9 \text { de maio de } 2005 \text { e aprovado em } 16 \text { de janeiro de } 2006}$ 